\title{
$\beta$-Lactamases in the Biochemistry and Molecular Biology Laboratory
}

Paula Amador, Cristina Prudêncio, Monica Vieira, Ricardo Ferraz, Rosalia Fonte, Nuno Silva, Pedro Coelho, and Ruben Fernandes

$\beta$-lactamases are hydrolytic enzymes that inactivate the $\beta$-lactam ring of antibiotics such as penicillins and cephalosporins. The major diversity of studies carried out until now have mainly focused on the characterization of $\beta$-lactamases recovered among clinical isolates of Gram-positive staphylococci and Gram-negative enterobacteria, amongst others. However, only some studies refer to the detection and development of $\beta$-lactamases carriers in healthy humans, sick animals, or even in strains isolated from environmental stocks such as food, water, or soils. Considering this, we proposed a 10-week laboratory programme for the Biochemistry and Molecular Biology laboratory for majors in the health, environmen-tal, and agronomical sciences. During those weeks, students would be dealing with some basic techni-ques such as DNA extraction, bacterial transformation, polymerase chain reaction (PCR), gel electropho-resis, and the use of several bioinformatics tools. These laboratory exercises would be conducted as a mini research project in which all the classes would be connected with the previous ones. This curricu-lum was compared in an experiment involving two groups of students from two different majors. The new curriculum, with classes linked together as a mini research project, was taught to a major in Phar-macy and an old curriculum was taught to students from environmental health. The results showed that students who were enrolled in the new curriculum obtained better results in the final exam than the students who were enrolled in the former curriculum. Likewise, these students were found to be more enthusiastic during the laboratory classes than those from the former curriculum.

Keywords: Curriculum development, genomics proteomics bioinformatics, laboratory exercises, recombinant DNA technology, integration of research into undergraduate teaching.

Biochemistry and molecular biology (BMB) are the units that are uniquely positioned to engage undergraduate students in interdisciplinary research in response to the Bologna Process, which emphasizes multidisciplinary projects. To prepare undergraduates for careers who cross disciplinary boundaries, students need to practice interdisciplinary communication in academic programs that connect students in diverse disciplines. At present, the syllabus includes laboratory classes of BMB for a diversity of majors, including future allied health professionals and bioscience engineers, such as biotechnology, biomedical, agronomical, or food technology. A common criticism of many traditional undergraduate laboratory experiences is that each lab session is an isolated activity unrelated to the following week's lab. Such lab activities leave students with an inaccurate view of how scientific research is conducted [1]. Bacterial transforma- tion, DNA and protein extraction, polymerase chain reaction (PCR), agarose gel electrophoresis (AGE), and bioinformatics analysis were practical skills developed during 1 trimester (10 weeks) of either freshman/sophomore years.

In all the cases, the unifying story that supports the classes has focused on antibiotic resistance due to the presence of $\beta$-lactamases (EC 3.5.2.6) hydrolytic enzymes. Since antibiotic resistance is a worldwide problem concerning public health which has been extensively associated to the antibiotic use [2, 3]. According to the last report from the European Surveillance of Antimicrobial Consumption (ESAC project), $\beta$-lactams, such as penicillins and cephalosporins, are by far the most commonly used antibiotics prescribed and consumed in Europe [4].

ANTIBIOTIC RESISTANCE: ITS IMPORTANCE FOR HEALTH AND BIOSCIENCE ENGINEERING STUDIES

In general terms, the interest of these studies is to enable the understanding of drug resistance mechanisms 
presented by pathogen prokaryotic microorganisms, since microbial drug resistance has been increasing in the last years, constituting nowadays one of the major clinical problems [5]. This problem also arises in the food industry, aquaculture, livestock, and animal production, with the increase of resistance food additives, preservatives, and antibiotics used in prophylactic procedures to avoid infections caused by the lack of hygiene. Among the antibiotics used for these purposes, $\beta$-lactams are the most used [6]. These $\beta$-lactam antimicrobial agents are the most common treatment for bacterial infections. Rates of bacterial resistance to these agents are increasing worldwide and the production of $\beta$-lactamases is the most common mechanism of bacterial resistance $[7,8]$.Microorganisms carrying genes encoding for $\beta$ lactamases have been isolated from multiple sources, both food and clinical isolates [9, 10].

\section{THE CLASSES}

Classes of 3 hours were designed to develop a project (Table I) in which a gene of antibiotic resistance, a $\beta$-lactamase enzyme, would be inserted and expressed in wild-type bacteria in a way to promote process skill development within content-rich pedagogy and to connect text-based and laboratory-based learning with the world of contemporary research. This new syllabus was tested in one of the majors while the old curriculum was used simultaneously in another major which was also used as a control. The students of the major in Pharmacy were used as the study group in which the new curriculum was applied to. The students of Environmental Health were used as the control group.

\section{MATERIALS AND METHODS USED IN THE CLASSES}

The microorganisms in these classes may include E. coli K-12, DH5 $\alpha$, JM101, JM109, XL1-Blue among other commercialized by biotech companies. Likewise, the vector compatible with these classes may be any that harbours a gene of resistance to ampicillin, such as pGEM (Stratagene), pBAD (Invitrogen), pET (Invitrogen) among others. The plasmid used in these experiments was the pGLO (Bio-Rad) that has the advantage to har-bour a gene coding for the green fluorescent protein (GFP) as well. All the other chemicals and medium reac-tive were also purchased from biotech companies. In the electrophoresis lesson, the laboratory exercise involves the use of potentially harmful chemicals (e.g. ethidium bromide) and equipment (e.g. UV transilluminators). For that reason, the use of safe UV DNA stains such as SYBR Safe DNA stains (Invitrogen) or even the Fast Blast DNA Stain (Bio-Rad) that avoids the use of UV transilluminators is recommended.

\section{The First Week}

In the first week, the overall project was presented to the students. The students were then invited to form groups that would be fixed though out the remainder of the following classes. Each group made contact with the objectives, programme as well as with all the major hazards and pitfalls. Students were also asked to acquire a lab notebook and to record all the steps.

\section{The Second Week}

The students performed a simplified transformation method that involves resuspending the bacteria by adding a large bacterial colony to a microcentrifuge tube containing $250 \mu \mathrm{L}$ of a sterile $50 \mathrm{mM}$ calcium chloride solution $\left(-20^{\circ} \mathrm{C}\right)$. After which $10 \mathrm{ng}$ of the plasmid DNA is added and the blend is left to cool down for $15 \mathrm{~min}$. A step of heat shock for 45 seconds at $42^{\circ} \mathrm{C}$ is followed and there-after the solution is cool down again in ice and is plated on a LB medium containing ampicillin and left to incubate in a oven at $37^{\circ} \mathrm{C}$ overnight. The next class is usually not on the following day, therefore, teachers may have to put the LB plates in the freezer $\left(4^{\circ} \mathrm{C}\right)$ until the next class.

\section{The Third Week}

Students analysed the plates and counted the number of colony forming units (CFU) to calculate the transform-

TABLE I

Laboratory schedule and learning goals

\begin{tabular}{|c|c|c|}
\hline Week & Activity & Learning goals \\
\hline 2 & Transforming bacteria & $\begin{array}{l}\text { Students will understand the concept of chemically competent cell } \\
\text { Students will understand how cell may have acquired foreign DNA by heat shock }\end{array}$ \\
\hline 3 & Analyzing recombinants & $\begin{array}{l}\text { Students will be able to read a simple plasmid (pGLO) map } \\
\text { Students will be able to select the transformant strains }\end{array}$ \\
\hline 4 & DNA extraction & Students will understand the steps of the organic phase DNA extraction \\
\hline 5 & $\begin{array}{l}\text { Bioinformatics I-Alignment } \\
\text { and primer design }\end{array}$ & $\begin{array}{l}\text { Students will be able to use a sequence of the pGLO plasmid and align with sequence of the } \\
\text { bla gene using BLAST } \\
\text { Students will be able to design primers with primer-BLAST }\end{array}$ \\
\hline 6 & PCR & Students will be able to perform a PCR assay \\
\hline 7 & Gel electrophoresis & $\begin{array}{l}\text { Students will be able to perform an agarose gel electrophoresis } \\
\text { Students will understand the staining methods for DNA }\end{array}$ \\
\hline 8 & $\begin{array}{l}\text { Standard curve } \\
\text { construction and analysis }\end{array}$ & $\begin{array}{l}\text { Students will be able to use a semilog paper to plot a curve of an molecular weight standard } \\
\text { Students will understand the weight determination of a specific band using a standard curve } \\
\text { plotted in semilog paper }\end{array}$ \\
\hline 9 & $\begin{array}{l}\text { Bioinformatics II-2D } \\
\text { gel localization }\end{array}$ & $\begin{array}{l}\text { Students will be able to use the molecular structure viewer Cn3D } \\
\text { Students will understand the combination of the IEF electrophoresis with the SDS-PAGE } \\
\text { Students will search on a 2D gel database the enzyme } \beta \text {-lactamase }\end{array}$ \\
\hline
\end{tabular}

bla gene, $\beta$-lactamase gene; PCR, polymerase chain reaction; IEF, isoelectric focusing; SDS-PAGE, sodium dodecyl sulfate polyacrylamide gel electrophoresis; 2D gel, two dimension gel. 
ing efficiency. The transformation efficiency was calculated by the total number of CFU on the agar plate/ amount of DNA spread on the agar plate. Generally the cloning kits contain the plasmid map. For this reason if the plasmid used was acquired from a biotech company or if the teacher possesses the plasmid map it should be distributed to students in order for them to analyze it.

\section{The Fourth Week}

Briefly, the extraction of DNA proposed was based on organic phase extraction. A single colony should be left to grow from a solid medium culture in $50 \mathrm{~mL}$ of $\mathrm{LB}$ overnight or 6-8 hours prior to the lab class at $37^{\circ} \mathrm{C}$ with agitation. The medium must be supplemented with ampicillin $(100 \mu \mathrm{g} / \mathrm{mL})$.

In the class, students may transfer the solution into a 15 falcon tube and the cells should pellet by centrifugation for $10 \mathrm{~min}$ at maximum speed, and resuspended in $5 \mathrm{~mL} 50 \mathrm{mM}$ TRIS ( $\mathrm{pH}$ 8.0), $50 \mathrm{mM}$ EDTA. The cell suspension is then frozen at $-70^{\circ} \mathrm{C}(10 \mathrm{~min})$. Hereafter, 0.5 $\mathrm{mL} 250 \mathrm{mM}$ TRIS ( $\mathrm{pH}$ 8.0) must be added to $10 \mathrm{mg} / \mathrm{mL}$ lysozyme. The mixture must be transferred into the frozen suspension and thawed at room temperature. When melted, the suspension is placed on ice for $45 \mathrm{~min}$. Then, $1 \mathrm{~mL}$ of $0.5 \%$ SDS, $50 \mathrm{mM}$ TRIS (pH 8.0), $0.4 \mathrm{M}$ EDTA, $1 \mathrm{mg} / \mathrm{mL}$ proteinase $\mathrm{K}$ must be added and placed in a $50^{\circ} \mathrm{C}$ water bath for $30 \mathrm{~min}$. DNA was extracted with $6 \mathrm{~mL}$ phenol:chloroform:isoamyl alcool 25:24:1 (APPLICHEM) at $10,000 \mathrm{rpm}$ for $15 \mathrm{~min}$. The top layer is transferred into a new tube. A volume 1:10 of $3 \mathrm{M}$ sodium acetate $\mathrm{pH} 5.2$ must be added to the new tube and mixed gently, following which $2 \times$ volume of $70 \%$ ethanol is added and mixed by inverting and followed by a centrifugation step at $10,000 \mathrm{rpm}$ for $5 \mathrm{~min}$. The top layer is again transferred to a new tube. A volume 1:10 of $3 \mathrm{M}$ sodium acetate should be added to the new tube and mixed gently, then $2 \times$ volume of $70 \%$ ethanol is added and mixed by inverting. DNA is then spooled out and dissolved in $2 \mathrm{~mL}$ in ultrapure quality distilled water and then frozen until the next class.

Note that to accelerate the laboratory exercise all solutions must be prepared prior to the class and if it is possible numbered as follow: solution I, solution II, and so on.

\section{The Fifth Week}

In this class students were invited to explore some bioinformatic tools available online at BLAST from the National Centre Biotechnology Institute. If you are using pGLO, the whole sequence may be found at http:// srv2.lycoming.edu/ newman/bioinformatics/pglo.seq or at the GenBank with the accession number U62637.1. A lot of activities may be explored at BLAST Home (http:// blast.ncbi.nlm.nih.gov/Blast.cgi). At first, the plasmid genetic map should be viewed at GenBank. Teachers may ask some simple questions such as "How many genes do you find in this plasmid?" and "What is the size in base pairs of the genes araC, gfpuv, and bla?". The correct answers are: three genes and to the second question 879,720 , and 861 base pairs, respectively. Be sure that students understand the mathematical calcula- tion for the gene size determination. For example, the araC is located from the base 96 to 974 . The intuitive calculation is to subtract 96 from 974 which is 719 . However, the gene has 720 base pairs since the first base also belongs to the gene. Hence, the correct formula is the last base minus the first base plus one. Another important tool for this class is to pick and align primers of the bla gene from the plasmid and preview the length of the amplicon. This task may be achieved with another tool that may be found in the BLAST homepage. That is the new application named Primer-BLAST - http:// www.ncbi.nlm.nih.gov/tools/primer-blast/index.cgi?LINK_ $\mathrm{LOC}=$ BlastHomeAd. Briefly, the bla gene in FASTA format must be copied from GenBank. Another window must be opened in Primer-BLAST. Then the gene must be pasted in the field of "PCR Template." FASTA format title for this gene may be a little intuitive (>gi|1490531:2636-3496 Cloning vector pBAD-GFPuv, complete sequence), however, it may be easily changed for something more instinctive (>pGLO-bla). Then in the field "Primer Parameters" in the forward primer, the following sequence should be entered, AGTATTCAACATTTCCGTGTCG and in the reverse primer the sequence ATACCGCGCCACATAGCAGAA (both sequences are written from $\left.5^{\prime}-3^{\prime}\right)$. If you want only to determine the complementarities between primers and gene, you only have to click in "Get Primers" at the bottom of the page. Otherwise, conditions may be changed as well as other primer pairs. The result of this search will be a graph that shows the complementarities regions and a table that summarizes some aspects such as the amplicon length (232 bp) and GC\% or $T_{\mathrm{m}}$ (melting temperature) among others.

\section{The Sixth Week}

For the PCR class, the use of AmpliTaq Gold ${ }^{\mathbb{B}}$ Fast PCR Master Mix (Applied Biosystems ${ }^{\mathbb{R}}$ ) is recommended, which is concentrated to fold the usage concentration. Briefly, per group, students must mix $12.5 \mu \mathrm{L}$ of the master mix, $1 \mu \mathrm{L}$ of each primer, and $1 \mu \mathrm{L}$ DNA which was obtained previously, in the fourth week. Ultrapure quality distilled water must be added up to a final volume of $25 \mu \mathrm{L}(9.5 \mu \mathrm{L})$. The amplification programme at the thermocycler must include three stages. In the first stage, the samples are heated up to $94^{\circ} \mathrm{C}$ for $4 \mathrm{~min}$ and 30 seconds. Then, in the second stage, of 30 cycles, the samples are submitted to three steps. The first is $30 \mathrm{sec}-$ onds at $94^{\circ} \mathrm{C}$, the second is 30 seconds at $56^{\circ} \mathrm{C}$, and finally a third step of 60 seconds at $72^{\circ} \mathrm{C}$. Not all the thermocyclers allow the final stage. However, if the class is in the late afternoon, it is highly recommended a final stage of $4{ }^{\circ} \mathrm{C}$ until the next morning. Finally, and regarding this class, it is recommended that students prepare another tube, besides the one that contains their DNA from the recombinant clone, containing $1 \mu \mathrm{L}$ of water instead of DNA as negative control.

\section{The Seventh Week}

In this laboratory exercise, students prepared an agarose gel and performed an electrophoresis to visualize 
the PCR reaction product obtained in the previous week. Since the product is too small, a $2 \%$ agarose powder is diluted in 0.5xTBE and placed on the microwave until boil. Unlike bromide ethidium, SYBR ${ }^{\circledR}$ Safe DNA gel stain (Invitrogen) may be heated in the microwave. This staining must be diluted in a 1:10,000 proportion. If the tray in use needs $60 \mathrm{~mL}$ of melted agarose, $6 \mu \mathrm{L}$ of SYBR ${ }^{\circledR}$ Safe DNA gel stain (Invitrogen) must be added. The samples may also be mixed in an Orange $G$ loading buffer and loaded into the wells. A $50 \mathrm{bp}$ molecular ruler is also recommended, due to the small size of the amplicon. The gel must be registered or photographed to the next class.

\section{The Eighth Week}

During this week, students plotted the molecular ruler bands onto a semilog paper to make a standard curve. Briefly, with the picture taken of the gel of the previous week, students measured in milimeters $(\mathrm{mm})$ some of the bands present in the molecular ruler (according to the manufacturer). Then they plotted those measurements on the semilog paper. Base pairs on the $Y$ axis (log scale) while the migration distance of the bands on the $X$ axis (decimal) as in Fig. 1. The teacher may invite the class to discuss the importance of such step. Then, it must be explained that if one did not previously know the molecular weight $(\mathrm{MW})$ of the band in base pairs, this method could be a very good and generally accurate alternative. In this case, the amplicon should migrate about 88-89 $\mathrm{mm}$, which would correspond to a $230 \mathrm{bp}$ band.

\section{The Ninth Week}

Another bioinformatics approach was proposed, this time to explore some protein tools. First of all, students should be able to access to internet computer terminals. Moreover, Cn3D programme (structure viewer) should be installed on all computer terminals. The last version, Cn3D 4.1, is available for PC, Mac, and Unix (freeware) at http://www.ncbi.nlm.nih.gov/Structure/CN3D/cn3d.shtml.

In the first part of the session, the class should discuss the several types of protein electrophoresis, in particular those that are used to determine the MW of proteins such as the polyacrylamide gel electrophoresis with sodium dodecyl sulphate (SDS-PAGE) and the electrophoresis used to determine the isoelectric point (pl), that is, isoelectric focusing (IEF). Then, students should discuss the advantages, disadvantages, and applications of two-dimensional polyacrylamide gel electrophoresis (2DPAGE) for both $\mathrm{MW}$ and pl. Afterwards, students are invited to enter in a 2D-PAGE database (http://www. expasy.ch/ch2d/), to find some proteins. In this particular case, the class should search for "beta-lactamase." The query will end in one result with the access number P00811. Click on the enzyme and then in 2D-PAGE small image to amplify it. The picture generated will be similar to Fig. 2. When clicking on the red star, more information will appear on the screen

Later, in the same session, students will again enter the GenBank to use the molecular structure viewer, the Cn3D version 4.1. Remember that the access number of

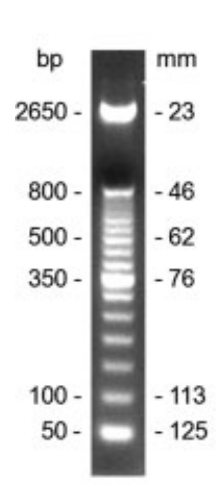

a bp

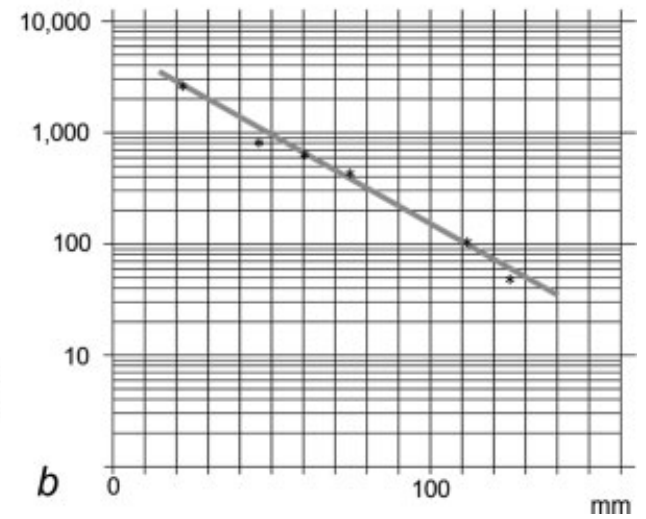

FIG. 1. Standard curve from a 50 bp molecular ruler. (a) Tracklt' 50 bp DNA ladder (Invitrogen), the MW in base pairs of the bands were provided by manufacturer and the migration in millimeters was determined in the study from a photograph. (b) Construction of the standard curve in semilog paper according to the migration distance of each band ( $\mathrm{mm}$ ) and their MW in base pairs (bp).

the plasmid in use is U62637.1. After which, students must click on the protein id, that for the $\beta$-lactamase gene is/protein_id="AAC53664.1." Another window will open and the students must click on the conserved domain database (CDD) number that for the $\beta$-lactamase gene is /db_xref="CDD:120312.deselect domains, change colors, among others. Students generally get excited with this part of the exercise.

\section{The Tenth Week}

In this final week, students presented their reports to the class and discussed all the results. This last week was also used to overview the "mini-project" and explain some misunderstandings and doubts that could still be remaining.

\section{ASSESSMENT OF THE CLASSES}

To assess the students' perception of how much they had learned from the entire trimester's lab experience, a retrospective evaluation was constructed which was administered to BMB students from two different majors (Pharmacy and Environmental Health) from the same year, from the same school and with BMB different teachers' but from the same department. In the Pharmacy major the curriculum as described previously was implemented. In the Environmental Health major the former curriculum was employed. Briefly, the former curriculum included bacterial transformation with pGLO plasmid and the study of the protein synthesis regulation by arabinose, PCR for the gfp gene, chemical properties of carbohydrates (Benedict and Lugol tests), the study of Krebs cycle and it's inhibition by malonate and a triglycerides and cholesterol quantification using point-of-care (POC) systems.

At the end of the trimester the new curriculum students completing the BMB evaluation period presented an average of $7.2 \pm 1.1$ (in a scale from 0 to 10 ) while students from old curriculum presented an average of $6.5 \pm 1.7$. 


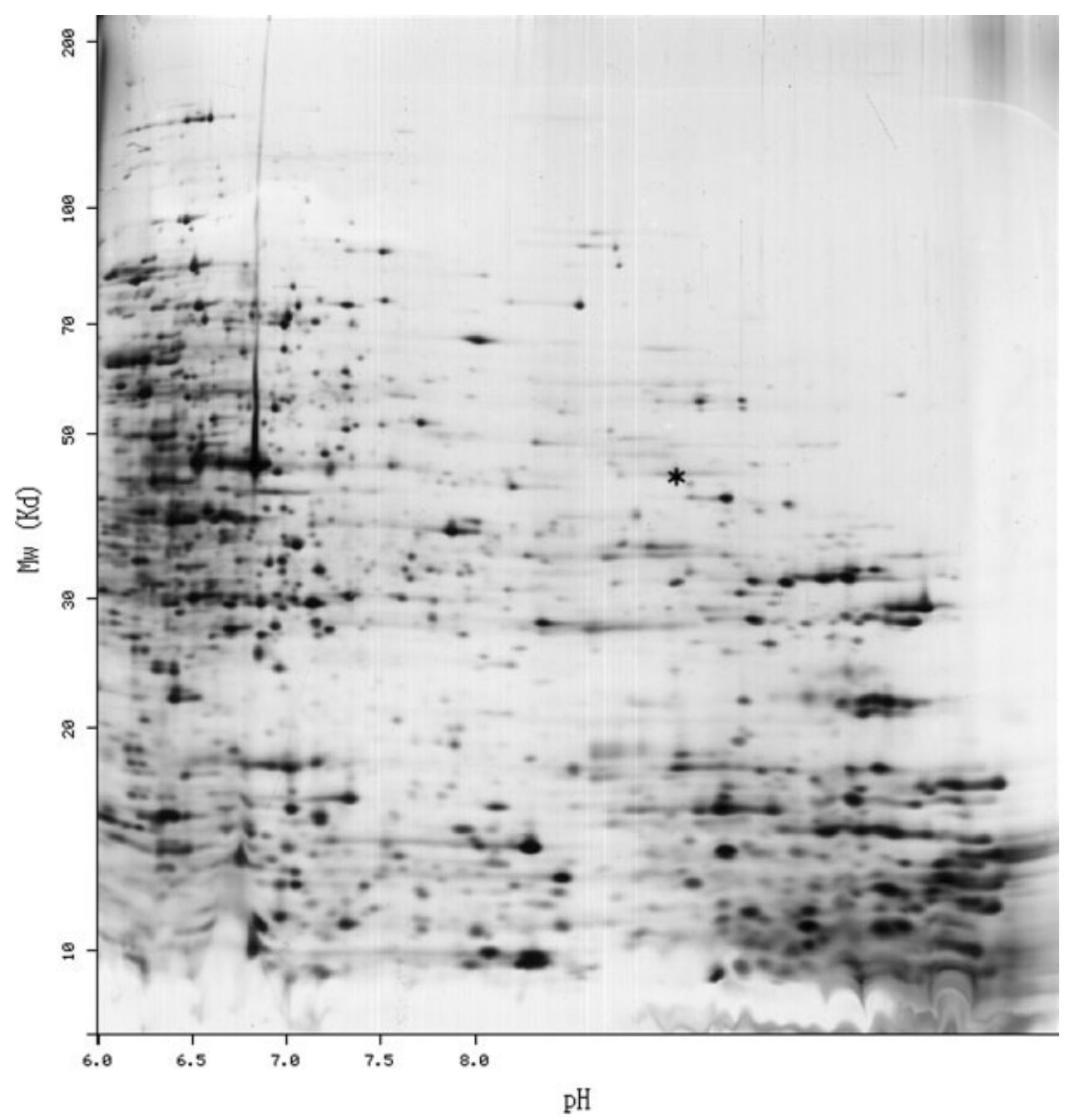

FIG. 2. Two-dimensional polyacrylamide gel electrophoresis (2D-PAGE) map. In this 2D-PAGE map, for the organism Escherichia coli, asterisk shows the location of $\beta$-lactamase (Accession number P00811). This image was obtained from the site of Swiss Institute of Bioinformatics with permission.

TABLE II

Questionnaire for the student's evaluation of the BMB lab experience (Adapted from Mitchell and Graziano, 2006)

\begin{tabular}{lcc}
\hline Question & Former curriculum $(n=17)$ & New curriculum $(n=38)$ \\
\hline 1. The BMB lab sessions were well organized & $3.9 \pm 0.8$ & $4.3 \pm 0.6$ \\
2. The BMB lab sessions stimulated active participation & $3.9 \pm 0.7$ & $4.2 \pm 0.7$ \\
3. The BMB lab sessions were import for the understanding & $3.7 \pm 1.0$ & $4.1 \pm 0.7$ \\
of theoretical concepts & $3.7 \pm 0.7$ & $4.0 \pm 0.6$ \\
4. The readings given by the lecturers were useful for the following & & $4.0 \pm 0.6$ \\
learning concepts & $3.6 \pm 0.8$ & $2.7 \pm 1.0$ \\
5. The BMB lab session constituted a valuable tool for learning & $2.7 \pm 0.8$ & $3.8 \pm 0.6$ \\
6. The number of students by class was high & $3.5 \pm 0.7$ & $4.2 \pm 0.8$ \\
7. The themes studied were wide and included a high variety of methods & $3.7 \pm 0.7$ & $3.7 \pm 0.7$ \\
8. The BMB lab sessions make easier to understand the scientific process & $3.6 \pm 0.7$ & \\
9. The BMB lab sessions contributed to understand the relation & & $4.1 \pm 0.7$ \\
between lab experiments and scientific progression & $3.9 \pm 0.6$ & $3.7 \pm 0.5$ \\
10. During the trimester you felt improvements in terms of: & $3.5 \pm 1.0$ & $3.8 \pm 0.4$ \\
10(a). Acquisition of technical and laboratory competences & $3.7 \pm 0.8$ & \\
10(b). Writing scientific reports & & $3.8 \pm 0.4$ \\
10(c). Understand the scientific language & $3.6 \pm 0.4$ & $3.6 \pm 0.5$ \\
11. Regarding other subjects/courses in BMB lab sessions you felt & $3.5 \pm 0.6$ & $3.8 \pm 0.5$ \\
improvements in terms of: & $3.6 \pm 0.6$ & $4.2 \pm 0.5$ \\
11(a). Acquisition of technical and laboratory competences & $4.0 \pm 0.9$ & \\
11(b). Writing scientific reports & & \\
11(c). Understand the scientific language & & \\
12. Looking back, the experience was useful & & \\
\hline
\end{tabular}

Mean responses \pm SD are shown.

The questionnaire was answered using a typical Likert scale: Strongly disagree; Disagree; Neither agree or disagree; Agree; and Strongly Agree. 
Regarding the retrospective evaluation that was administered to BMB students from the two different curricula it has allowed to get feedback from these students and compare the perception of how much they have learned from those who were enrolled in the new curriculum of BMB with the ones who were enrolled in the traditional course (Table II; page 305). The questionnaire was organized in 16 questions with close answers structured in Likert scale from 1 to 5 , in which 1 means "total disagreement" while 5 means "total agreement."

\section{DISCUSSION AND CONCLUSIONS}

The overall results seem to be very consistent in the sense that students who were enrolled in the new curriculum seemed to be more enthusiastic when answering the questions. This enthusiasm may be explained by their participation in these classes. During the trimester they seem very interested to participate in the new tasks, but also referred that they had to work more in order not to forget important concepts from previous laboratory exercises. This increased investment may also explain the differences observed between the grades of the two groups of students.

A more detailed analysis from the results also shows that the responses are consistent between the two groups, as for example in the response to question 6. The number of students per group in the two groups is the same and both groups are in agreement that this number of students per group is appropriate. Nevertheless, in all the other questions related with their perception of how much they have learned, the students enrolled in the new curriculum generally think that their type of class has contributed more for their learning than those that were taught by the former curriculum. In general, the students from the new curriculum think that lab sessions were well organized, stimulated the active participation, were important for the understanding of theoretical concepts and constituted a valuable learning tool. These students also think that the new BMB sessions made it easier to understand the scientific process and also felt an important improvement during the trimester in terms of the acquisition of technical and laboratory competences. Curiously, this feeling of improvement in terms of technical and practical laboratory competences was also strongly felt by students from old curriculum and both groups felt that, from a retrospective point of view, the experience was useful.

Regarding to financial aspects, both syllabus were quite similar in terms of costs. The new curriculum was slightly cheaper but one must not forget that the initial investment could be a negative factor for some less flexible budgets. Another flexibility related issue, is the fact that some topics and practical exercises that were excluded and that are potentially important, must be integrated in another subject and ideally, all the subjects from the department, should use the same philosophy and be worked as a whole.

The results reinforce the importance of the learning focused on the students [11-13]. The co-responsibility in their own learning must be encouraged. This co-respon- sibility is reflected in the adoption of an equalitarian part between the teacher and the student, being an active element motivated in a dynamic process of learning. Thus, it will be possible to treat the students not as clients, but as co-producers of their own education [14]. The laboratory exercise enables the students to learn basic concepts and techniques through applied examples with clinic relevance in the area of their future professions [15]. It seems clear that active learning must be encouraged, as it seems to better contribute for final competences acquired by the students and thus to better future professionals [16].

Acknowledgment-The authors express their gratitude to Mr. António da Conceição for the language reviewing and to all the students who kindly participated in this study.

\section{REFERENCES}

[1] B. F. Mitchell, M. R. Graziano (2006) From organelle to protein gel: A 6-wk laboratory project on flagellar proteins, CBE Life Sci. Educ. 5, 239-246.

[2] S. Coenen, M. Ferech, K. Dvorakova, E. Hendrickx, C. Suetens, H. Goossens (2006) European surveillance of antimicrobial consumption (ESAC): Outpatient cephalosporin use in Europe, J. Antimicrob. Chemother. 58, 413-417.

[3] B. E. Malmvall, S. Mölstad, J. Darelid, A. Hiselius, L. Larsson, J. Swanberg, P. E. Abom (2007) Reduction of antibiotics sales and sustained low incidence of bacterial resistance: Report on a broad approach during 10 years to implement evidence-based indications for antibiotic prescribing in Jönköping County, Sweden, Qual. Manag. Health Care. 16, 60-67.

[4] M. Ferech, S. Coenen, S. Malhotra-Kumar, K. Dvorakova, E. Hendrickx, C. Suetens, H. Goossens (2006) European surveillance of antimicrobial consumption (ESAC): Outpatient antibiotic use in Europe, J. Antimicrob. Chemother. 58, 401-407.

[5] P. M. Hawkey (2008) Molecular epidemiology of clinically significant antibiotic resistance genes, Br. J. Pharmacol. 153, 406-413.

[6] E. K. Silbergeld, J. Graham, L. B. Price (2008) Industrial food animal production, antimicrobial resistance, and human health, Annu. Rev. Public Health 29, 151-169.

[7] D. M. Livermore (2007) Introduction: The challenge of multiresistance, Int. J. Antimicrob. Agents. 29, 1-7.

[8] Y. Michel-Briand (2007) Resistance to the latest beta-lactams: Mechanisms of acquisition and spread of resistance in enterobacteriaceae, Bull. Acad. Nat. Med. 191, 35-50.

[9] P. Amador, R. Fernandes, C. Prudêncio, L. Brito (2009) Resistance to $\beta$-lactams in bacteria isolated from different types of Portuguese cheese, Int. J. Mol. Sci. 10, 1538-1551.

[10] R. Fernandes, A. Gestoso, J. M. Freitas, P. Santos, C. Prudêncio (2009) High resistance to fourth-generation cephalosporins among clinical isolates of enterobacteriaceae producing extended-spectrum beta-lactamases isolated in Portugal, Int. J. Antimicrob. Agents 33, 184-185.

[11] H. Barrows, in H. G.Schimdt, M. L.De Volder, Eds. (1984) A Specific, Problem-Based, Self-Directed Learning Method Designed to Teach Medical Problem Solving Skills, Self-Learning Skills and Enhance Knowledge Retention and Recall, Tutorials in ProblemBased Learning, van Gorcum Publishers, Maastricht.

[12] H. Barrows, M. Peters (1984) How to Begin Reforming the Medical Curriculum, Southern Illinois University Scholl of Medicine, Springfield, pp. 16-32.

[13] M. A. Albanese, S. Mitchell (1993) Problem-based learning: A review of literature on its outcomes and implementation issues, Acad. Med. 68, 52-81.

[14] R. Canário (1999) Educação De Adultos: Um Campo e Uma Problemática, Colecção Educa, Lisboa.

[15] R. Fernandes, R. Correia, R. Fonte, C. Prudêncio (2005) Human salivary $\alpha$-amylase (EC.3.2.1.1): Activity and PAS staining: A useful tool to study polysaccharides properties, Biochem. Mol. Biol. Educ. 34, 294-299.

[16] C. Madden (2005) Undergraduate nursing students' acquisition and retention of CPR knowledge and skills, Nurse Educ. Today, 26, 218-227. 